\title{
O programa nacional de alimentação escolar e a gestão municipal: eficiência administrativa, controle social e desenvolvimento local
}

\section{(}

ORIGINAL | ORIGINAL

National school meal program and municipal

administration: management efficiency, social

participation and local development

Walter BELIK ${ }^{1}$

Nuria Abrahão $\mathrm{CHAIM}^{2}$

\section{RE S U M O}

\section{Objetivo}

Avaliar o perfil da gestão pública municipal do Programa Nacional de Alimentação Escolar de 670 prefeituras inscritas no Prêmio Gestor Eficiente da Merenda Escolar, entre os anos de 2004 e 2005.

\section{Métodos}

Este estudo foi realizado a partir da inscrição de municípios de todo o Brasil no Prêmio Gestor Eficiente da Merenda Escolar, organizado pela Organização Não Governamental Ação Fome Zero. A inscrição é feita de forma voluntária e os municípios fornecem informações em relação a aspectos financeiros, formas de administração do Programa, compra de produtores rurais, atuação do Conselho de Alimentação Escolar e outras ações relacionadas à execução do Programa Nacional de Alimentação Escolar. Em seguida, a Organização Não Governamental confere os dados comparando-os com relatórios oficiais, a partir da realização de visitas.

\section{Resultados}

Verificou-se que a principal forma de administração do Programa Nacional de Alimentação Escolar é a centralizada (citada por mais de $80 \%$ das prefeituras inscritas nos dois anos). A grande maioria dos municípios inscritos em 2004 (90,1\%) e em 2005 (84,0\%) complementou o repasse de recursos do Governo Federal. O custo médio da refeição foi de $R \$ 0,31$ (para as inscritas em 2004) e de $R \$ 0,34$ para as inscritas em 2005. Em relação à compra de gêneros alimentícios, 26,1\% das prefeituras inscritas em 2004 e 30,4\% das inscritas em 2005 declararam comprar diretamente de produtores rurais.

\footnotetext{
1 Universidade Estadual de Campinas, Instituto de Economia. Cidade Universitária Zeferino Vaz, Caixa Postal 6135, 13083-970, Campinas, SP, Brasil. Correspondência para/Correspondence to: W.BELIK <belik@eco.unicamp.br>.

2 Universidade de Karlsruhe, Instituto de Estudos Regionais. Alemanha.
} 
596 W. BELIK \& N.A. CHAIM

\section{Conclusão}

A execução do Programa Nacional de Alimentação Escolar assume características próprias em cada município brasileiro. Identificar o perfil da administração pública, assim como as características das prefeituras que se destacaram no Prêmio, permite a implantação de ações que melhorem a execução do Programa.

Termos de indexação: Administração pública. Alimentação escolar. Políticas públicas. Programas e políticas de nutrição e alimentação.

\section{A B S T R A C T}

\section{Objective}

The objective was to assess the municipal public management profile of the National School Meal Program in 670 municipalities enrolled in the Efficient Manager of School Meals Prize between 2004 and 2005.

\section{Methods}

This study was based on the enrollment of municipalities throughout Brazil in the Efficient Manager of School Meals Prize, organized by the non-governmental organization Ação Fome Zero (Zero Hunger Action). Enrollment is voluntary and the municipalities supply information regarding the financial aspects and ways to administer the Program, purchase of produce, participation in the School Food Council and other activities associated with the National School Meal Program. The non-governmental organization then checks the data by comparing it with official reports done during visits.

\section{Results}

The National School Meal Program is mainly administered in a centralized manner as declared by more than $80 \%$ of the city halls enrolled during those two years. Most of the municipalities enrolled in 2004 (90.1\%) and 2005 (84.0\%) added funds to those received from the federal government. The average cost of the meal was $R \$ 0.31$ for the municipalities enrolled in 2004 and $R \$ 0.34$ for those enrolled in 2005. Regarding produce purchase, $26.1 \%$ of the city halls enrolled in 2004 and $30.4 \%$ of those enrolled in 2005 declared having bought straight from producers.

\section{Conclusion}

Each Brazilian municipality has its own way of carrying out the National School Meal Program. Identifying the profile of the public administration as well as the city halls that performed well in the Prize allows for the implementation of actions that improve the execution of the Program.

Indexing terms: Public administration. School meals. Public policies. Food and nutrition programs and policies.

\section{N T R O D U Ç Ã O}

O Programa Nacional de Alimentação Escolar (PNAE) completou, em 2004, 50 anos de existência. Após mais de meio século de funcionamento, o PNAE está presente em quase todos os municípios brasileiros e é considerado o maior programa de suplementação alimentar no Brasil, tendo em vista sua abrangência e seu alcance ${ }^{1}$.

A alimentação escolar desempenha um papel fundamental no processo de aprendizagem e desenvolvimento do aluno, ao mesmo tempo em que também garante um suprimento mínimo de alimentos às populações carentes. Dentro desse contexto, o PNAE pode ser considerado um importante programa de garantia à segurança alimentar no Brasil ${ }^{2,3}$.

A definição clássica do conceito de Segurança Alimentar deriva das resoluções tomadas na Cúpula Mundial da Alimentação, realizada pela Food and Agriculture Organization (FAO), em Roma, no ano de 1996, a saber: "A segurança alimentar existe quando toda pessoa, em todo momento, tem acesso físico e econômico a alimentos suficientes, inócuos e nutritivos para satisfazer suas necessidades alimentares e preferências quanto aos alimentos a fim de levar uma vida saudável e ativa"4. 
O presente trabalho utiliza o banco de dados de ações municipais em alimentação escolar montado a partir das centenas de inscrições recebidas por ocasião do Prêmio Gestor Eficiente da Merenda Escolar, organizado pela Organização Não Governamental (ONG) Ação Fome Zero, nos anos de 2004 e 2005.

A ONG Ação Fome Zero é uma associação civil sem fins lucrativos, criada em 2003 e mantida por contribuições de empresas, com o objetivo de elaborar e implantar projetos na área de segurança alimentar, entre eles o Projeto Gestão Eficiente da Merenda Escolar, que proporcionou a geração do banco de dados utilizado no presente trabalho. A entidade lançou essa nominação visando a dar destaque aos municípios com melhor desempenho na gestão do Programa Nacional de Alimentação Escolar. A partir das informações fornecidas pelas prefeituras inscritas, conferidas pelo corpo técnico da entidade, foi possível tecer parâmetros de atuação, identificar o que as boas administrações municipais estão realizando e, finalmente, apresentar conclusões e recomendações sobre o tema.

\section{Histórico do programa nacional de alimentação escolar}

O Programa Nacional de Alimentação Escolar teve origem em 1954, com a criação da Comissão Nacional de Alimentação (CNA), vinculada ao setor de Saúde Pública do Ministério da Saúde. Denominado, à época, Programa Nacional de Merenda Escolar, seu objetivo principal era reduzir a deficiência nutricional de estudantes carentes do Brasil'5.

Na sua fase inicial, o Programa tinha uma ação focalizada, mas, com o tempo, foi ganhando abrangência nacional e, em 1988, a alimentação escolar passou a ser um direito garantido pela Constituiçãa ${ }^{5}$. Segundo o Artigo 208 da Constituição Federal, "O dever do Estado com a educação será efetivado mediante a garantia de: VII atendimento ao educando, no ensino fundamental, a partir de programas suplementares de material didático-escolar, transporte, alimentação e assistência à saúde" ${ }^{\prime 6}$.

Outro grande avanço ocorreu em 1994, a partir da descentralização do Programa Nacional de Alimentação Escolar (Lei n. 8913) ${ }^{7}$. Com a descentralização, a Fundação de Assistência ao Estudante (FAE), órgão vinculado ao Ministério da Educação e Cultura e responsável pelo PNAE, estabeleceu convênios com estados e municípios para o repasse de recursos financeiros ${ }^{8}$. Mas este repasse ficou condicionado à criação dos Conselhos de Alimentação Escolar (CAE) em cada estado e município do País, que deveriam fiscalizar e controlar a aplicação dos recursos destinados à merenda escolar e também acompanhar a elaboração dos cardápios (atividade que passou a ser de responsabilidade dos estados e municípios) ${ }^{9}$.

A partir de 1997, a Fundação de Assistência ao Estudante (FAE) foi substituída pelo Fundo Nacional de Desenvolvimento da Educação (FNDE), desde então responsável pelo Programa Nacional de Alimentação Escolar.

A administração da alimentação escolar de forma descentralizada permitiu racionalizar a logística e os custos de distribuição dos produtos, além de viabilizar o oferecimento de uma alimentação escolar condizente com os hábitos da população nas diferentes localidades do País. As compras institucionais descentralizadas também abriram a possibilidade de inserção da pequena empresa, do comércio local, do pequeno produtor agrícola e da pecuária local nesse mercado institucional. E a criação dos CAE por sua vez possibilitou aos membros da comunidade escolar uma maior proximidade em relação à gestão do PNAE.

O CAE, a partir de 2000, passou a ser constituído por sete membros: um representante do Poder Executivo, um do Legislativo, dois representantes de professores, dois de pais de alunos e um representante da sociedade civil ${ }^{10}$. O Conselho é um órgão deliberativo, fiscalizador e de assessoramento, sendo que, entre suas funções, estão: acompanhar a aplicação dos recursos federais, zelar pela qualidade dos produtos adquiridos para 
598 W. BELIK \& N.A. CHAIM

o Programa e também emitir um parecer anual sobre as prestações de contas do PNAE. Esse parecer pode fazer com que os futuros repasses sejam interrompidos, caso seja constatada alguma irregularidade na gestão municipal ou estadual ${ }^{11}$.

Atualmente, o Programa Nacional de Alimentação Escolar é considerado o maior programa de suplementação alimentar no Brasil, o que se revela em termos de número de beneficiários e municípios atendidos. Para ter uma idéia do que representam estes números, 36,4 milhões de beneficiários em $2005^{12}$ correspondiam a cerca de $20 \%$ da população brasileira (considerando a estimativa do Instituto Brasileiro de Geografia e Estatística (IBGE) para o mesmo ano ${ }^{13}$ ) ou, ainda, cerca de $70 \%$ da população da faixa etária correlata - de 0 a 14 ${ }^{(3)}$, cuja adesão, segundo dados da Pesquisa Nacional por Amostra de Domicílio (PNAD) de 2004 era de 97,3\% para creches, $92,3 \%$ para pré-escola e $83,8 \%$ para o ensino fundamental.

Em termos de evolução da cobertura, o PNAE atendia um total de 137 municípios em 1955, fornecendo refeições para 85 mil crianças, no ano de sua criação. Passados 50 anos, o Programa cobre, praticamente, todos os municípios do País e atendeu em 2005, como já ressaltado, 36,4 milhões de crianças e adolescentes da educação infantil e do ensino fundamental da rede pública de ensino ${ }^{12}$. Em 2009, o PNAE passou a atender também, obrigatoriamente, o ensino médio configurando-se como um dos maiores programas de atendimento universal na área de educação no cenário mundial.

\section{M É TODOS}

\section{Perfil dos municípios analisados nas edições de 2003 e 2005}

O Prêmio Gestor Eficiente da Merenda Escolar foi elaborado pela ONG Ação Fome Zero, com o objetivo de avaliar e classificar as prefeituras do Brasil com relação à gestão da alimentação escolar. O lançamento do prêmio foi realizado em 2004, e em 2005 foi realizada a $2^{a}$ edição. O formulário de inscrição, composto de diversas perguntas que deveriam ser respondidas pela própria prefeitura, foi enviado a todos os municípios do País.

Com a utilização das informações contidas nos formulários, foi elaborado um ranking dos municípios, a partir da combinação de diferentes indicadores. Os indicadores quantitativos consideraram aspectos financeiros, nutricionais, impactos do Programa na economia local e atuação do Conselho de Alimentação Escolar. A composição de cada grupo de indicadores, elaborada com base nas edições de 2004 e 2005 do Prêmio Gestor Eficiente da Merenda Escolar, é descrita a seguir.

Aspectos financeiros: complementação municipal em relação ao recurso total para o PNAE; complementação municipal em relação à receita total bruta do município; recurso total gasto por aluno em relação à receita bruta do município per capita; recursos não gastos em relação ao recurso disponível.

Aspectos nutricionais: número de refeições por aluno; número de alunos por nutricionista; número de refeições por merendeira; número de escolas com refeitório; freqüência de cursos de educação alimentar para alunos e capacitação para merendeiros; dias de atendimento; adequação nutricional do cardápio declarado.

Desenvolvimento local: recursos gastos com produtores locais em relação ao total de recursos; quantidade de itens adquiridos; presença de escolas com hortas.

Atuação do Conselho de Alimentação Escolar: número de reuniões do $\mathrm{CAE}$; forma de escolha do representante da sociedade civil

Além dos indicadores quantitativos apresentados, os municípios inscritos no Prêmio Gestor foram avaliados qualitativamente, considerando os projetos desenvolvidos e outras iniciativas devidamente anexadas ao formulário de inscrição.

3 População estimada pelo IBGE para 2005: 184184264 e a população de 0 a 14: 50069427. 


\section{RESULTADOS}

Nas duas primeiras edições do prêmio, 729 prefeituras se inscreveram (396 em 2004 e 333 em 2005). Retirando-se as desclassificadas (por documentação incompleta ou pelo envio do formulário fora do prazo de inscrição), 670 prefeituras foram analisadas (383 em 2004 e 287 em 2005). A partir desse conjunto de questionários aplicados a um número expressivo de prefeituras, foi possível traçar um perfil da execução do PNAE nos dois anos mencionados.

São apresentados abaixo alguns aspectos relevantes desta análise. Todos os dados referem-se aos anos de 2003 e 2004 (que correspondem ao período de análise estabelecido na inscrição), e não permitem comparação já que o grupo de municípios inscritos em um ano é totalmente independente do grupo de inscritos do ano subseqüente.

Inscrições feitas em 2004 (dados referentes a 2003) foram: 383 municípios; 41376423 habitantes; 12756 escolas; 4694458 alunos (11,3\% do número de habitantes); 923158246 refeições servidas; $R \$ 286.307 .148,79$ de recursos gastos com alimentação escolar; $\mathrm{R} \$ 36.588 .712 .325,06$ em receita municipal bruta; $\mathrm{R} \$ 884,29$ de receita por habitante.

Inscrições feitas em 2005 (dados referentes a 2004) foram: 287 municípios; 29726578 habitantes; 9045 escolas; 3435492 alunos (11,6\% do número de habitantes); 680457297 refeições servidas; $R \$ 230.697 .083,38$ de recursos gastos com alimentação escolar; $\mathrm{R} \$ 29.618 .060 .553,77$ em receita municipal bruta $\mathrm{R} \$ 996,35$ de receita por habitante.

Dos dados gerais apresentados acima, verifica-se que, para cada aluno, foi gasto, entre os municípios inscritos em 2004, aproximadamente, $R \$ 61,00$ durante o ano letivo, em que foram servidas 197 refeições por aluno (o que daria, aproximadamente, uma refeição por dia por aluno durante os 200 dias previstos pela Resolução do PNAE). Entre os inscritos em 2005, o valor gasto por aluno durante o ano letivo ficou em, aproximadamente, $R \$ 67,00$ e 198 foi o número médio de refeições servidas por aluno durante o ano letivo. Estes dados médios serão analisados com mais detalhes nos itens seguintes.

Frente ao número de inscritos no Prêmio, observa-se que grande parte é proveniente das Regiões Sudeste e Sul do País, conforme descrito na Tabela 1.

Muito embora haja uma predominância da Região Sudeste quanto ao número de inscrições, quando relacionados com o número de municípios de cada região, a distribuição se modifica, e, nota-se que a participação da Centro-Oeste em relação ao número de municípios da região não fica tão distante das Regiões Sul e Sudeste

\section{As formas de gestão do PNAE}

Existem duas modalidades de operacionalização do Programa: a centralizada e a escolarizada.

Tabela 1. Distribuição regional dos municípios inscritos no Prêmio Gestor Eficiente da Merenda Escolar, 2004 e 2005.

\begin{tabular}{|c|c|c|c|c|c|c|}
\hline Região & $\begin{array}{c}\text { Inscrições em } \\
2004 \text { (n) }\end{array}$ & $\begin{array}{c}\text { Inscritos }{ }^{*} \\
(\%)\end{array}$ & $\begin{array}{l}\text { Municípios da } \\
\left.\text { região** }^{*} \%\right)\end{array}$ & $\begin{array}{l}\text { Inscrições em } \\
2005^{*}(n)\end{array}$ & $\begin{array}{c}\text { Inscritos }^{*} \\
(\%)\end{array}$ & $\begin{array}{c}\text { Municípios da } \\
\text { região (\%) }\end{array}$ \\
\hline Sudeste & 169 & 44,1 & 10,1 & 126 & 43,9 & 7,6 \\
\hline Sul & 121 & 31,6 & 10,4 & 104 & 36,2 & 8,8 \\
\hline Nordeste & 50 & 13,1 & 2,8 & 30 & 10,5 & 1,7 \\
\hline Centro-Oeste & 30 & 7,8 & 8,7 & 19 & 6,6 & 4,1 \\
\hline Norte & 13 & 3,4 & 2,9 & 8 & 2,8 & 1,8 \\
\hline Total & 383 & 100,0 & & 287 & 100,0 & \\
\hline
\end{tabular}

Fonte dos dados brutos: Prêmio Gestor Eficiente da Merenda Escolar, 2004 e 2005

* Participação em relação ao total de inscritos; ${ }^{* *}$ Participação em relação ao número de inscritos. 
600 W. BELIK \& N.A. CHAIM

A centralização ocorre quando as prefeituras executam o Programa em todas as suas fases, ou seja, recebem, administram e prestam contas do recurso federal, são responsáveis pela aquisição e distribuição dos alimentos e também pela elaboração dos cardápios. Já na escolarização as prefeituras transferem os recursos diretamente para as creches e escolas pertencentes à sua rede, que passam a se responsabilizar pela execução do Programa11. É possível, também, que haja uma combinação das duas modalidades de gestão, o que se chama de gestão mista. Observou-se que a forma preponderante de gestão entre os municípios estudados é a centralizada, nos dois anos analisados (87,7\% em 2004 e 83,2\% em 2005). A forma escolarizada esteve presente em $7,6 \%$ dos municípios inscritos em 2004 e em 9,8\% dos inscritos em 2005. Já a mista foi mencionada em $4,7 \%$ e $7,0 \%$ das prefeituras, de 2004 e 2005 , respectivamente.

Uma grande vantagem da forma centralizada é a possibilidade de realizar um controle eficaz de todo o processo e garantir que a qualidade dos produtos e dos cardápios seja aplicada em todas as escolas do município. Além disso, a centralização confere um maior poder de negociação da prefeitura frente aos fornecedores, o que pode levar a uma redução de gastos (considerando que o volume de compra é maior).

Por outro lado, a escolarização pode facilitar a logística na distribuição de produtos perecíveis, como verduras, frutas e legumes e poderia trazer como vantagem o fato de que os produtos utilizados estejam mais frescos, já que a cadeia de distribuição seria mais curta. Porém, a compra descentralizada implica em um maior trabalho no controle e na fiscalização do processo de compra e execução do Programa.

Alguns municípios optaram por um sistema misto, combinando as vantagens da forma centralizada para a compra de produtos não perecíveis, como arroz, feijão e macarrão, e da forma escolarizada para a compra de hortifrutícolas.

Ainda dentro do sistema centralizado, algumas prefeituras podem optar pela contratação de empresas fornecedoras de alimentação, é o chamado sistema terceirizado, muito polêmico entre os profissionais da área. A empresa contratada pode ou não utilizar a estrutura e a mão-de-obra escolar, sendo que a prefeitura paga pelo número de refeições servidas. Dos municípios estudados, uma pequena parcela $(2,9 \%$ dos casos, ou seja, 11 prefeituras inscritas em 2004, e 2,4\%, 7 prefeituras em 2005), utilizava o sistema terceirizado.

Um dos aspectos discutidos refere-se ao fato de que a terceirização, muitas vezes, implicaria em custos maiores para a prefeitura, já que esta paga não apenas pelo alimento servido, mas também pelo serviço prestado. Outro aspecto questionado refere-se ao fato de que a lógica de funcionamento de uma empresa privada não segue a mesma lógica da administração pública, o que significaria um risco ao fornecimento de uma alimentação escolar adequada.

\section{Repasse de recursos}

A composição dos recursos totais gastos com alimentação escolar segue a ordem apresentada na Tabela 2, ou seja, a maior parcela do

Tabela 2. Composição dos recursos empregados na alimentação escolar.

\begin{tabular}{lcccc}
\hline Recursos & Valores (R\$) 2004 & Composição (\%) 2004 & Valores (R\$) 2005 & Composição (\%) 2005 \\
\hline Repasse FNDE & $114.920 .199,63$ & 40,1 & $97.536 .486,61$ & 41,7 \\
Complementação do município & $162.545 .607,67$ & 56,8 & $132.390 .294,07$ & 56,5 \\
Repasse estadual & $8.841 .341,49$ & 3,1 & $4.261 .925,41$ & 1,8 \\
\hline Total & $286.307 .148,79$ & 100,0 & $234.188 .706,09$ & 100,0 \\
\hline
\end{tabular}

Fonte dos dados brutos: Prêmio Gestor Eficiente da Merenda Escolar, 2004 e 2005

*FNDE: Fundo Nacional de Desenvolvimento da Educação. 
valor total é oriunda de recursos dos próprios municípios (próximo a 56\%, nos dois anos), como complementação à verba repassada pelo Governo Federal. Esta porcentagem pode ser considerada alta, já que a lei prevê que a obrigação de fornecer alimentação escolar é tanto do Governo Federal quanto estadual e municipal, no entanto não estipula o valor ou o percentual desta complementação.

Do total de 383 municípios, inscritos em 2004 , apenas 38 prefeituras $(9,9 \%)$ não complementaram a verba federal, sendo esse o caso de 46 municípios (16\%) em 2005.

Esse montante, no entanto, representa menos de $1 \%$ da Receita Total Bruta Municipal para a maioria dos municípios inscritos em 2004 e 2005. Apenas para 17,2\% das prefeituras em 2004 e para 12,9\% em 2005, a complementação superou a faixa de $1 \%$ da Receita Bruta Municipal. Vale observar, contudo, que, nesse montante, estão incluídos apenas os gastos com a compra alimentos.

\section{Custo médio das refeições}

As prefeituras inscritas em 2004 apresentaram, para cada refeição servida por dia por aluno, um custo médio de $\mathrm{R} \$ 0,31$ (considerando apenas a compra de alimentos). Já para as pre- feituras inscritas em 2005, o custo médio de cada refeição foi de $\mathrm{R} \$ 0,34$ (considerando também apenas gasto com gêneros alimentícios). Na Tabela 3 é possível observar como foi a distribuição deste custo para o total de municípios analisados.

O custo de cada refeição depende diretamente do total de recursos gastos, do número de refeições servidas e do número de dias de atendimento.

Vale notar que nenhum dos extremos, tanto o menor custo quanto o maior custo por refeição, podem ser considerados bons exemplos de gestão. No caso dos valores mínimos, porque sequer gastaram os $R \$ 0,13$ ou $R \$ 0,15$ (a partir de meados de 2004) a que tinham direito, dando indícios de uma gestão pouco eficiente. $E$, no segundo caso, o alto custo da merenda pode sugerir uma má administração que teria acarretado gastos excessivos.

\section{Desenvolvimento local}

Em resposta à questão sobre compra de gêneros alimentícios diretamente de produtores rurais locais para a alimentação escolar, a porcentagem de prefeituras que responderam positivamente foi de apenas $26,1 \%$ (em 2004) e 30,3\% (em 2005), o que representa um total de 100 e 87 prefeituras, respectivamente.

Tabela 3. Número de municípios por custo de refeição servida pelo Programa Nacional de Alimentação Escolar, por dia por aluno.

\begin{tabular}{lcc}
\hline \multirow{2}{*}{ Custo diário da refeição servida } & \multicolumn{2}{c}{ Municípios inscritos $(\mathrm{n})$} \\
\cline { 2 - 3 } & 2004 & 2005 \\
\hline Até $R \$ 0,15$ & 90 & 51 \\
$\mathrm{R} \$ 0,16$ a $\mathrm{R} \$ 0,20$ & 91 & 70 \\
$\mathrm{R} \$ 0,21$ a $\mathrm{R} \$ 0,30$ & 86 & 62 \\
$\mathrm{R} \$ 0,31$ a $\mathrm{R} \$ 0,50$ & 79 & 63 \\
$\mathrm{R} \$ 0,51$ a $\mathrm{R} \$ 0,80$ & 29 & 32 \\
Acima de $\mathrm{R} \$ 0,81$ & 8 & 9 \\
\hline Total & 383 & 287 \\
\hline Menor valor gasto & $\mathrm{R} \$ 0,10$ & $\mathrm{R} \$ 0,09$ \\
Maior valor gasto & $\mathrm{R} \$ 2,94$ & $\mathrm{R} \$ 1,10$ \\
Valor médio & $\mathrm{R} \$ 0,31$ & $\mathrm{R} \$ 0,34$ \\
\hline
\end{tabular}

Fonte dos dados brutos: Prêmio Gestor Eficiente da Merenda Escolar, 2004 e 2005. 
602 W. BELIK \& N.A. CHAIM

O valor médio de gastos com compras locais por município foi de $\mathrm{R} \$ 48.083,84$ em 2004 e R\$ 65.507,11 em 2005. Em 2004 e em 2005 o menor valor gasto ficou em pouco mais de $\mathrm{R} \$ 130,00$ e o valor máximo acima de $\mathrm{R} \$ 520$ mil (para inscritas em 2004) e acima de $R \$ 590$ mil (inscritas em 2005). E, entre as prefeituras que compravam de produtores locais, os principais gêneros adquiridos foram frutas, legumes, verduras e leite.

Percebe-se que existe um número maior de municípios de pequeno porte (até 100 mil habitantes) na compra de produtores rurais locais, e que estes municípios estão localizados, principalmente, nas Regiões Sudeste e Sul. Estes dados acompanham o perfil dos locais estudados, uma vez que há uma concentração de inscrições nestas regiões e um número considerável de pequenos municípios inscritos (em 2004 cerca de $84 \%$ das prefeituras - 321 cidades - possuíam até 100 mil habitantes e em 2005 o percentual foi próximo de $83 \%$ - 238 cidades). Dessa forma, quando a análise é feita em relação ao número de municípios pequenos, médios, grandes e capitais de estados que se inscreveram no Prêmio, é possível perceber que a participação de municípios pequenos na compra de produtores rurais não se sobressai em relação aos demais (Tabela 4). Estes dados podem indicar que, nem sempre a possibilidade de comprar de produtores rurais está associada ao tamanho do município (considerando o número de habitantes), mas, possivelmente, à existência ou não de políticas municipais que incentivem a aproximação dos produtores locais ao mercado institucional de compra de alimentos vinculado ao PNAE.

Em relação à região onde se fazem as aquisições de alimentos, a análise feita, considerando o total de inscritos por região, também revela que a participação de municípios que compraram de produtores rurais não se concentra nos estados do Sul e Sudeste, mas se distribui de forma relativamente equilibrada entre regiões, com certo destaque para a região Centro-Oeste nos dois anos analisados (Tabela 5).

\section{Atuação dos conselhos de alimentação escolar}

Apesar de não estar definido oficialmente na legislação (Resolução FNDE n 32 de 10 de agosto de 2006) o número de reuniões que o Conselho deve fazer durante o ano, normalmente são sugeridas reuniões mensais, ou, pelo menos, encontros a cada 2 ou 3 meses, para que seja possível acompanhar toda a execução do Programa, pois se considera que apenas uma reunião anual para analisar a prestação de contas do PNAE e emitir o parecer conclusivo do CAE não seja

Tabela 4. Municípios que compraram de produtores rurais locais alimentos destinados ao Programa Nacional de Alimentação Escolar em 2004 e 2005, em relação ao tamanho.

\begin{tabular}{|c|c|c|c|c|}
\hline $\begin{array}{l}\text { Tamanho } \\
\text { (em número de } \\
\text { habitantes) }\end{array}$ & $\begin{array}{l}\text { Municípios que } \\
\text { compraram de produtores } \\
\text { rurais em } 2004 \text { (n) }\end{array}$ & $\begin{array}{l}\text { Percentual em relação } \\
\text { ao número de } \\
\text { inscritos }\end{array}$ & $\begin{array}{l}\text { Municípios que } \\
\text { compraram de produtores } \\
\text { rurais em } 2005 \text { (n) }\end{array}$ & $\begin{array}{l}\text { Percentual em } \\
\text { relação ao número } \\
\text { de inscritos }\end{array}$ \\
\hline $\begin{array}{l}\text { Municípios pequenos (até } \\
100 \text { mil habitantes) }\end{array}$ & 77 & 23,9 & 71 & 29,8 \\
\hline $\begin{array}{l}\text { Municípios médios ( } 100 \\
\text { mil a } 500 \text { mil habitantes) }\end{array}$ & 20 & 40,0 & 12 & 32,4 \\
\hline $\begin{array}{l}\text { Municípios grandes (aci- } \\
\text { ma de } 500 \text { mil habitantes) }\end{array}$ & - & - & 1 & 25,0 \\
\hline Capitais de Estados & 3 & 42,9 & 3 & 37,5 \\
\hline Total & 100 & & 87 & \\
\hline
\end{tabular}

Fonte dos dados brutos: Prêmio Gestor Eficiente da Merenda Escolar, 2004 e 2005. 
Tabela 5. Municípios que compraram alimentos destinados ao Programa Nacional de Alimentação Escolar de produtores rurais locais em 2004 e 2005, em relação à região.

\begin{tabular}{lcccc}
\hline Regiões & $\begin{array}{c}\text { Municípios que } \\
\text { compraram de produtores } \\
\text { rurais em 2004 (n) }\end{array}$ & $\begin{array}{c}\text { Percentual em relação } \\
\text { ao número de } \\
\text { inscritos }\end{array}$ & $\begin{array}{c}\text { Municípios que } \\
\text { compraram de produtores } \\
\text { rurais em 2005 (n) }\end{array}$ & $\begin{array}{c}\text { Percentual em } \\
\text { relação ao número } \\
\text { de inscritos }\end{array}$ \\
\hline Sudeste & 42 & 24,9 & 40 & 31,7 \\
Sul & 28 & 23,1 & 27 & 25,9 \\
Nordeste & 18 & 36,0 & 9 & 30,0 \\
Centro-Oeste & 10 & 60,0 & 9 & 47,4 \\
Norte & 2 & 15,4 & 2 & 25,0 \\
\hline Total & 100 & & 87 & \\
\hline
\end{tabular}

Fonte dos dados brutos: Prêmio Gestor Eficiente da Merenda Escolar, 2004 e 2005.

suficiente para que o Conselho exerça suas atribuições de forma adequada. Durante cursos para CAE, o próprio FNDE, assim como outros órgãos de fiscalização do PNAE, sugere que o Conselho reúna-se várias vezes ao ano, pois apenas dessa forma é possível acompanhar e fiscalizar a execução do Programa.

Observa-se, pelos documentos encaminhados pelos municípios, que o número médio de reuniões para as prefeituras inscritas na $1^{\text {a }}$ edição do prêmio foi de sete, e entre os inscritos em 2005 foi de seis, o que indica que a atuação dos CAEs nesses municípios é apenas razoável. Quando perguntados sobre a importância do CAE para o sucesso do Programa, a grande maioria respondeu que é grande ou muito grande, o que não é um indicativo de que o Conselho seja realmente valorizado ou que a população esteja empoderada para a realização do seu trabalho, de acordo com o reconhecimento do poder que pode ser exercido pelos próprios interessados no processo de desenvolvimento sustentável ${ }^{14}$. Apenas demonstra que existe uma consciência de que o Conselho deve ter um papel importante.

Nesse quadro, entretanto, existem municípios em que a participação dos conselheiros foi determinante para redirecionar os rumos da administração pública. Em alguns casos, o Conselho conseguiu barrar o processo de terceirização da alimentação escolar, exigir a contratação de nutricionista para atender ao Programa e assegurar a participação dos conselheiros nos processos de licitação e acompanhamento da aceitação do cardápio pelos alunos.

Vale lembrar que, em municípios em que o CAE lutou por mudanças ou impediu o desmantelamento da estrutura pública de atendimento ao escolar, o número de reuniões alcançou mais de 20 por ano.

\section{Informações gerais sobre a execução do PNAE}

Apesar de estar previsto em lei que o cardápio deve ser elaborado por nutricionista habilitado ${ }^{11}$, ainda podem ser verificados municípios que não têm nutricionista contratado (15,9\% dos municípios inscritos em 2004, o que significa 61 prefeituras e 79 municípios entre os inscritos em 2005 , o que corresponde a $27,5 \%$ do total). Já a grande maioria (mais de 74,0\% em 2004 e 60,0\% em 2005) dispõe apenas de um só profissional, o que, dependendo do número de escolas, é insuficiente.

Já em relação ao número de merendeiros, existiam, em média, 2,2 merendeiros por escola nos dados dos inscritos em 2004, o que proporcionava uma média de 159 refeições por dia por merendeira. Já entre os inscritos em 2005, a média de merendeiros por escola era de 2,7 , e que ficavam responsáveis por servir, em média, 148 refeições por dia.

Entre as iniciativas adotadas pela gestão municipal, a implantação de hortas escolares é a 
604 W. BELIK \& N.A. CHAIM

mais presente nos dois anos analisados: foi citada por 270 municípios (70,5\% do total - 2004) e 174 municípios (60,0\% do total - 2005). Para os inscritos em 2004, as hortas estavam presentes em 2145 escolas (25,4\% do total de escolas) e, no caso dos inscritos em 2005, em 1560 escolas (29,6\% do total de escolas).

Ao analisar o perfil dos municípios que declararam ter hortas escolares, foi possível notar que o percentual (em relação ao número de inscritos) foi elevado para municípios de todos os tamanhos, com destaque para as capitais inscritas em 2004, o que mostra, também, que esta iniciativa é viável, tanto em municípios pequenos quanto em grandes cidades.

O sistema de auto-serviço está presente em apenas $17 \%$ (referente a 2004) e em 11,5\% (referente a 2005) dos municípios, ou seja, na grande maioria, são os merendeiros que servem os alunos, seguindo o formato tradicional. Esse é um ponto importante, pois o sistema de auto-serviço pode fortalecer o trabalho de educação alimentar, de resgate da auto-estima e, até mesmo, de redução de desperdício, já que dá autonomia ao aluno e representa em si uma forma de avaliação do gosto, do aspecto e da apresentação do cardápio oferecido. Mas isto só é possível se houver o acompanhamento adequado de profissionais capacitados, para a devida orientação aos estudantes. Observa-se, entre os municípios estudados, que a maioria das escolas trabalha com o sistema tradicional, impedindo que essas inovações sejam incorporadas à alimentação escolar.

O número de prefeituras que apresentam escolas com refeitório (mesa e cadeira para que as crianças se alimentem) alcança o surpreendente índice de mais de $80 \%$ nas duas edições analisadas. Esse dado mostra que os municípios que se candidataram ao recebimento do Prêmio valorizam o refeitório, evitando a prática de servir a merenda no pátio da escola ou mesmo na sala de aula. A existência de refeitório para a alimentação do escolar pode ser um indicativo de que esse espaço físico seja mais do que simplesmente um local para comer, seja um espaço de socialização entre alunos e professores.

Os cursos de educação alimentar aos alunos ainda não são usuais entre as prefeituras analisadas, já que menos de 50,0\% delas oferecem este tipo de curso aos estudantes (nos dois anos de análise). E, entre as que oferecerem, estes são realizados em freqüência anual ou semestral. Por sua vez, a capacitação de merendeiros é uma prática mais comum entre as prefeituras, já que em $92,4 \%$ e $76,3 \%$ dos casos (dados referentes às inscrições de 2004 e 2005, respectivamente) esta prática foi realizada com freqüência semestral ou anual.

A partir da análise dos municípios inscritos, cujos aspectos gerais foram apresentados nos itens anteriores, foram escolhidos 22 casos de destaque, que receberam o seu reconhecimento em cerimônia pública, em termos de administração pública municipal. Estas práticas são apresentadas e discutidas no próximo item.

\section{I S C U S S Ã O}

As iniciativas destacadas nas duas edições do Prêmio Gestor Eficiente da Merenda Escolar evidenciam que, nessas prefeituras, a gestão do Programa de Alimentação Escolar não se restringe ao fornecimento de alimentação ao escolar, mas parte do princípio de que a sua gestão está inserida em uma rede de relações que envolve atores de diferentes segmentos, seja da área educacional, do setor econômico ou da sociedade civil. Essas prefeituras revelam que, talvez, o principal desafio não seja apenas o financeiro, mas sim o estabelecimento de uma rede de apoio local que sustente e permita que o Programa seja gerido de forma eficiente.

Nos municípios em que foi possível estabelecer essa rede de apoio, foi possível também acoplar ao PNAE programas de desenvolvimento local, educação alimentar, cidadania e mesmo de resgate e revalorização cultural. Dessa forma, pode-se dizer que as prefeituras vencedoras apre- 
sentaram como característica essencial (o que as destacou das demais administrações) o envolvimento de diferentes setores da sociedade, de forma a gerar um efeito multiplicador do esforço do município na gestão do Programa. Abaixo são apresentados alguns pontos importantes:

- Esforço financeiro: preocupação em investir na alimentação escolar, o que significa não restringir a execução do Programa apenas ao uso do repasse do FNDE, mas sim complementar, para garantir a qualidade necessária tanto em gêneros alimentícios quanto em recursos humanos e em estrutura física. A complementação municipal destas iniciativas premiadas alcança, em média, mais de 100\% do recurso federal, embora represente muito pouco em termos de orçamento municipal.

- Impulso ao desenvolvimento local: empenho em envolver os produtores, as associações e as cooperativas locais no mercado institucional de compra de alimentos para a merenda escolar. Este esforço se traduz em iniciativas criativas com o apoio de instituições de pesquisa, como os Institutos ou Empresas de Assistência Técnica e Extensão Rural (EMATER) dos estados, que possibilitam a organização, o aprimoramento da produção e a participação de concorrências para aquisição de alimentos para o fornecimento da alimentação escolar. Algumas prefeituras optaram também por criar leis municipais de incentivo à associação de agricultores locais, outras dão assistência técnica para a produção e a comercialização e algumas também utilizam programas governamentais, como o Programa de Aquisição de Alimentos (PAA). Dentro desta proposta de inclusão da produção local, o cardápio da alimentação escolar acaba resgatando a cultura alimentar regional e também promovendo ganhos em termos nutricionais.

- Investimento em alimentação de qualidade: a qualidade nutricional também é um ponto forte na execução do Programa destas prefeituras vencedoras. Entre as atividades adotadas, prezam-se a informação e a educação de alunos, de pais de alunos, de professores e merendeiros sobre alimentação saudável; a composição nutricional dos alimentos; e a importância em consumir frutas, legumes e verduras. Dessa forma, busca-se incentivar a adoção de bons hábitos na comunidade escolar e, assim, promover a adesão das crianças a um cardápio balanceado. Além disso, existe a preocupação em manter os merendeiros informados sobre doenças que são comuns a este tipo de trabalhador, como a obesidade, e reforçar as informações sobre questões de higiene na preparação da alimentação. Em muitas cidades, além da refeição principal, também é fornecido um café da manhã ou um reforço alimentar, principalmente em escolas de regiões mais carentes ou em escolas da zona rural. Para avaliar a adequação do cardápio, os nutricionistas fazem o acompanhamento nutricional das crianças beneficiárias. Algumas prefeituras vão além, ao produzir cardápios específicos para crianças celíacas e diabéticas. E muitas estão adotando alimentos orgânicos na alimentação escolar, o que é uma posição de vanguarda. Outra iniciativa importante, adotada por algumas prefeituras, é a regulamentação do que pode ser comercializado nas cantinas escolares, procurando retirar destas cantinas doces, salgadinhos industrializados, refrigerantes e frituras.

- Promoção de novas iniciativas: desenvolvimento de iniciativas criativas que têm um impacto positivo no funcionamento do sistema de alimentação escolar, tais como: a criação de hortas escolares e hortos municipais, com o aproveitamento deste espaço para cursos de educação alimentar e ambiental, além da utilização destes alimentos na alimentação escolar; o incentivo e a valorização dos merendeiros, com a realização de concursos para premiação dos profissionais que mais se destacaram, a realização de concursos de receitas e a publicação das receitas premiadas, ou, ainda, pela criação do Dia da Merendeira; e por fim destaca-se a criação de padarias municipais, em que está prevista a participação de alunos e o desenvolvimento de aulas de culinária.

- Envolvimento do Conselho de Alimentação Escolar: efetiva atuação do CAE. Em várias 
606 W. BELIK \& N.A. CHAIM

cidades muitas melhorias no sistema de alimentação escolar foram obtidas graças à participação ativa do CAE, que conseguiu chamar a atenção para o problema e mobilizar pais de alunos, professores e, até mesmo, vereadores e a imprensa. É possível relatar casos de CAE que conseguiram evitar a terceirização da alimentação escolar e conseguiram fazer com que fosse contratado um nutricionista para executar o Programa, com evidente economia de recursos públicos. Alguns Conselhos acompanharam mensalmente a prestação de contas do Programa e estavam sempre presentes para acompanhar desde a licitação e a aquisição de alimentos até a elaboração do cardápio e a aceitação da alimentação escolar pelos alunos. Em determinados municípios a composição do CAE é, em sua grande maioria, formada por membros da terceira idade, o que confere particularidades bastante positivas, pois a disponibilidade e o interesse deste grupo fazem com que o Conselho seja extremamente atuante.

\section{O N CLUS Ã O}

A análise da execução do Programa Nacional de Alimentação Escolar, nas cidades inscritas no Prêmio Gestor Eficiente da Merenda Escolar, evidencia que a gestão do Programa assume características próprias e se adapta ao contexto de cada município. No entanto, o perfil das administrações vencedoras indica que um fator determinante e diferenciador é a participação social, seja por meio da atuação ativa do Conselho de Alimentação Escolar, pelo envolvimento de pais de alunos, professores e merendeiros, ou pela inclusão de produtores locais no processo de aquisição de alimentos.

A gestão do Programa, quando realizada de forma compartilhada entre os atores envolvidos no processo, gera um impacto positivo nas várias áreas que o PNAE contempla. Na área nutricional, a alimentação nas escolas se configura como fator de promoção da reeducação alimentar e de revalorização da cultura alimentar local. Na área financeira, o Programa promove um maior envolvimento do poder local, o que se reflete em um maior investimento no próprio PNAE. Na área social, a presença do Programa significa uma maior adesão à alimentação escolar por parte dos alunos, um maior interesse e envolvimento da comunidade escolar - como pais e professores - com o objetivo de que a escola ofereça uma alimentação nutritiva e de boa aceitação. Além disso, o PNAE pode resultar em um impacto positivo para economia local, a partir da compra de alimentos de produtores locais.

Dessa forma, é importante ressaltar que investimentos isolados não geram os impactos positivos necessários para que a gestão, em todos os seus aspectos, possa ser considerada eficiente.

\section{COLABORADORES}

W. BELIK contribuiu com a concepção da pesquisa, a interpretação e a contextualização dos dados. N.A. CHAIM contribuiu com a organização das informações, a análise e a interpretação dos dados.

\section{REFER Ê NCIAS}

1. Turpin ME. A Alimentação escolar como vetor de desenvolvimento local e garantia da segurança alimentar [dissertação]. Universidade Estadual de Campinas; 2008.

2. Belik W. Políticas públicas, pobreza rural e segurança alimentar. In: Pochmann M, Fagnani E. Série debates contemporâneos, economia social e do trabalho n.1. São Paulo: LTr; 2007. p.180-95.

3. Takagi MA. Implantação da política de segurança alimentar e nutricional no Brasil: seus limites e desafios [tese]. Campinas: Universidade Estadual de Campinas; 2006.

4. Oganização das Nações Unidas para Agricultura. Alimentação para todos. Roma: FAO;1996.

5. Sturion, GL. Programa de alimentação escolar: avaliação do desempenho em dez municípios brasileiros [tese]. Campinas: Universidade Estadual de Campinas; 2002.

6. Brasil. Senado Federal. Constituição República Federativa do Brasil: art. 208 inciso VII: alimentação escolar como dever do estado. Brasília: Senado Federal; 1988. 
7. Brasil. Poder Legislativo. Lei $n^{\circ} 8913$, de 12 julho de 1994. Dispõe sobre a descentralização da merenda escolar. Diário Oficial da União. 199413 jul; 132(1):30.

8. Stefanini MLR. Merenda escolar: história, evolução e contribuição no atendimento das necessidades nutricionais da criança [tese]. São Paulo: Universidade de São Paulo; 1998.

9. Spinelli MAS, Canesqui AM. O Programa de alimentação escolar no estado de Mato Grosso: da centralização à descentralização (1979 - 1995). Rev Nutr. 2002, 15(1):105-17. doi: 10.1590S 1415-5273S210200100001.

10. Pipitone MA, Ometto AMH, Silva MV, Sturion GL, Furtuoso MCO, Oetterer M. Atuação dos conselhos municipais de alimentação escolar na gestão do programa nacional de alimentação escolar. Rev Nutr. 2003; 16(2):143-54. doi 10.1590/S141552732003000200001 .
11. Brasil. Ministério Educação. Fundo Nacional de Desenvolvimento da Educação. Resolução FNDE/ $\mathrm{CD} / \mathrm{n}^{\circ} 032$, de 10 de agosto de 2006. [acesso 2009 jan]. Disponível em: <ftp://ftp.fnde.gov.br/web/ resolucoes_2006/res032_10082006.pdf>.

12. Brasil. Ministério da Educação. Fundo Nacional de Desenvolvimento da Educação. [acesso 2009 jan]. Disponível em: <http://www.fnde.gov.br/home/ index.jsp?arquivo=alimentacao_escolar.html\# historico>.

13. Instituto Brasileiro de Geografia e Estatística. Pesquisa nacional por amostra de domicílio. Rio de Janeiro: IBGE; 2004.

14. Oakley P, Clayton A. Monitoramento e avaliação do empoderamento. São Paulo: Instituto Polis; 2003.

Recebido em: 9/11/2006

Versão final reapresentada em: 2/3/2009

Aprovado em: 6/7/2009 